\title{
Secukinumab in the treatment of psoriasis: patient selection and perspectives
}

This article was published in the following Dove Press journal:

Psoriasis: Targets and Therapy

\author{
Eric J Yang ${ }^{1,2}$ \\ Kristen M Beck' \\ Wilson Liao' \\ 'Department of Dermatology, \\ University of California San Francisco, \\ San Francisco, CA, USA; ${ }^{2}$ Chicago \\ Medical School, Rosalind Franklin \\ University of Medicine and Science, \\ North Chicago, IL, USA
}

\begin{abstract}
Secukinumab is a human monoclonal antibody targeting IL-17A that has been approved for three indications: moderate-to-severe plaque psoriasis, psoriatic arthritis, and ankylosing spondylitis. In Phase III clinical trials for each of these three indications, secukinumab has proven to be both highly efficacious and well-tolerated. However, several biologic medications are currently approved for the treatment of moderate-to-severe plaque psoriasis, and many demonstrate excellent efficacy and safety. Due to this wide selection, it is often unclear how to choose biologics for specific patients. Important considerations in biologic selection include clinical efficacy, safety, cost, convenience, onset of action, and management of comorbid disease. This article aims to outline the key considerations in patient selection for the treatment of plaque psoriasis with secukinumab.
\end{abstract}

Keywords: secukinumab, IL-17 inhibitor, IL-17A, biologics, psoriasis, patient selection

\section{Introduction}

Psoriasis vulgaris is associated with significant comorbidity including depression, ${ }^{1-3}$ increased risk of cardiovascular events, ${ }^{4,5}$ diminished quality of life,${ }^{6}$ as well as overall increased mortality. ${ }^{7}$ Furthermore, up to $40 \%$ of psoriasis patients have or will develop comorbid psoriatic arthritis in their lifetime. ${ }^{8}$ Effective treatment of this chronic, immune-mediated systemic inflammatory disease is necessary to improve quality of life and possibly decrease the risk of comorbid disease in psoriasis patients. ${ }^{9-11}$

Biologic medications currently approved for the treatment of moderate-to-severe plaque psoriasis include TNF- $\alpha$ inhibitors (adalimumab, etanercept, infliximab), IL-17 pathway inhibitors (ixekizumab, brodalumab, secukinumab), IL-12/IL-23 inhibitors (ustekinumab), and IL-23 inhibitors (guselkumab, tildrakizumab). Each medication has its own unique efficacy and safety profile. Dermatologists are fortunate to now have so many options available in the therapeutic armamentarium for moderate-tosevere psoriasis patients, but it can be difficult to select specific biologics for individual patients. This article outlines key considerations in patient selection for the treatment of plaque psoriasis with secukinumab.

\section{Practical considerations}

Secukinumab (Cosentyx ${ }^{\circledR}$, Novartis Pharmaceuticals Corporation, East Hanover, NJ, USA) is a recombinant human monoclonal IgG1 antibody that specifically binds to IL$17 \mathrm{~A}$ that has been approved for the treatment of adult patients with moderate-to-severe
Department of Dermatology, University of California San Francisco, 515 Spruce Street, San Francisco, CA 94II8, USA

$\mathrm{Tel}+\mathrm{I} 8583225414$

$\mathrm{Fax}+\mathrm{I} 4155024126$

Email ericjyang@outlook.com 
plaque psoriasis, active psoriatic arthritis, or active ankylosing spondylitis. $^{12}$

The recommended dosing for secukinumab differs for psoriasis as compared to psoriatic arthritis and ankylosing spondylitis. Recommended dosing for plaque psoriasis patients is $300 \mathrm{mg}$ administered subcutaneously at weeks 0 , $1,2,3$, and 4 (loading dose), and every 4 weeks thereafter (maintenance). ${ }^{12}$ However, a lower dosage of $150 \mathrm{mg}$ may also be used to improve tolerability. Patients with psoriatic arthritis or ankylosing spondylitis may use secukinumab with or without a loading dose. With a loading dose, $150 \mathrm{mg}$ secukinumab is administered at weeks $0,1,2,3$, and 4 (loading dose), and every 4 weeks thereafter (maintenance). Without a loading dose, $150 \mathrm{mg}$ secukinumab is administered every 4 weeks. If patients continue to have active psoriatic arthritis, they may benefit from increasing the dose to $300 \mathrm{mg}$. Patients with both psoriatic arthritis and moderate-to-severe psoriasis are advised to use the dosing recommendations for plaque psoriasis.

Secukinumab is supplied as single-use $1 \mathrm{~mL}$ autoinjector pens and $1 \mathrm{~mL}$ prefilled syringes with a 27-gauge fixed $1 / 2$-inch needle, each containing a $150 \mathrm{mg}$ dose of the medication. Secukinumab can also be reconstituted from a lyophilized powder by a health care professional, with each vial containing $150 \mathrm{mg}$ of the medication.

Secukinumab is contraindicated in patients with a hypersensitivity reaction to secukinumab or to any of its excipients. It is recommended to evaluate patients for tuberculosis infection prior to initiating treatment with secukinumab. Secukinumab should be avoided in patients with preexisting inflammatory bowel disease (IBD). Secukinumab may increase the risk for infection, and live vaccines should not be given to patients treated with secukinumab.

\section{Efficacy in plaque psoriasis}

Two pivotal randomized, controlled, double-blind Phase III trials evaluated the efficacy of secukinumab in patients with moderate-to-severe plaque psoriasis: ERASURE and FIXTURE. ${ }^{13}$ In all Phase III clinical trials for secukinumab for moderate-to-severe plaque psoriasis, patients in the treatment arm were dosed with $300 \mathrm{mg}$ secukinumab administered once weekly for 5 weeks, then every 4 weeks thereafter (Table 1).

Secukinumab was compared with placebo in ERASURE and placebo or etanercept in FIXTURE. ${ }^{13}$ The coprimary efficacy endpoints in both studies were the proportion of patients treated with secukinumab who achieved $\geq 75 \%$ reduction in Psoriasis Area and Severity Index (PASI 75) and Investigator's Global Assessment (IGA) 0/1 at week 12 as compared to placebo. Both trials achieved these coprimary endpoints, with a significantly greater proportion of patients at week 12 achieving PASI 75 on secukinumab (ERASURE: 81.6\%, FIXTURE: $77.1 \%$ ) compared to placebo (ERASURE: 4.5\%, FIXTURE: $4.9 \%$ ) or etanercept (FIXTURE: $44.0 \%$ ), and a significantly greater proportion of patients achieving IGA $0 / 1$ on secukinumab (ERASURE: $65.3 \%$, FIXTURE: $62.5 \%$ ) compared to placebo (ERASURE: $2.4 \%$, FIXTURE:

Table I Summary of key Phase III clinical trial results of secukinumab for the treatment of plaque psoriasis at week 12

\begin{tabular}{|c|c|c|c|c|c|c|c|}
\hline Trial & Year & $\mathbf{n}$ & Treatment (n) & IGA $0 / I^{a}$ & PASI 75 & PASI 90 & PASI 100 \\
\hline \multirow[t]{3}{*}{ ERASURE $^{13}$} & 2014 & 738 & Secukinumab, 300 mg (245) & $65.3 \%$ & $81.6 \%$ & $59.2 \%$ & $28.6 \%$ \\
\hline & & & Secukinumab, $150 \mathrm{mg}$ (245) & $51.2 \%$ & $71.6 \%$ & $39.1 \%$ & $12.8 \%$ \\
\hline & & & Placebo (248) & $2.4 \%$ & $4.5 \%$ & $1.2 \%$ & $0.8 \%$ \\
\hline \multirow[t]{4}{*}{ FIXTURE ${ }^{13}$} & 2014 & 1,306 & Secukinumab, 300 mg (327) & $62.5 \%$ & $77.1 \%$ & $54.2 \%$ & $24.1 \%$ \\
\hline & & & Secukinumab, $150 \mathrm{mg}$ (327) & $51.1 \%$ & $67.0 \%$ & $41.9 \%$ & $14.4 \%$ \\
\hline & & & Etanercept (326) & $27.2 \%$ & $4.0 \%$ & $20.7 \%$ & $4.3 \%$ \\
\hline & & & Placebo (326) & $2.8 \%$ & $4.9 \%$ & $1.5 \%$ & $0.0 \%$ \\
\hline \multirow[t]{2}{*}{ CLEAR $^{14}$} & 2015 & 676 & Secukinumab, $300 \mathrm{mg}$ (337) & $80.8 \%$ & $91.0 \%$ & $72.8 \%$ & $38.9 \%$ \\
\hline & & & Ustekinumab (339) & $65.1 \%$ & $79.1 \%$ & $53.4 \%$ & $25.7 \%$ \\
\hline \multirow[t]{2}{*}{ SCULPTURE' ${ }^{16}$} & 2015 & 966 & Secukinumab, $300 \mathrm{mg}(484)$ & - & $90.1 \%$ & - & - \\
\hline & & & Secukinumab, $150 \mathrm{mg}$ (482) & - & $84.4 \%$ & - & - \\
\hline \multirow[t]{3}{*}{ FEATURE $^{18}$} & 2014 & 177 & Secukinumab, 300 mg (59) & $69.0 \%$ & $75.9 \%$ & $60.3 \%$ & $43.1 \%$ \\
\hline & & & Secukinumab, I50 mg (59) & $52.5 \%$ & $69.5 \%$ & $45.8 \%$ & $8.5 \%$ \\
\hline & & & Placebo (59) & $0.0 \%$ & $0.0 \%$ & $0.0 \%$ & $0.0 \%$ \\
\hline \multirow[t]{3}{*}{ JUNCTURE ${ }^{19}$} & 2014 & 182 & Secukinumab, 300 mg (60) & $73.3 \%$ & $86.7 \%$ & $55.0 \%$ & $26.7 \%$ \\
\hline & & & Secukinumab, $150 \mathrm{mg}(6 \mathrm{I})$ & $53.3 \%$ & $71.7 \%$ & $40.0 \%$ & $16.7 \%$ \\
\hline & & & Placebo (6I) & $0.0 \%$ & $3.3 \%$ & $0.0 \%$ & $0.0 \%$ \\
\hline
\end{tabular}

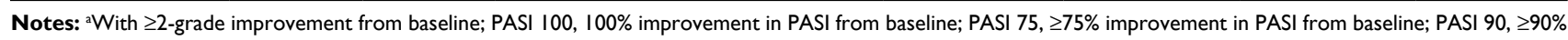
improvement in PASI from baseline.

Abbreviations: IGA, Investigator's Global Assessment; PASI, Psoriasis Area and Severity Index. 
$2.8 \%$ ) or etanercept $(27.2 \%)$. Additionally, secukinumab demonstrated significantly improved PASI 90 (ERASURE: 59.2\%, FIXTURE: $20.7 \%$ ) and PASI 100 (ERASURE: 28.6\%, FIXTURE: $24.1 \%$ ) responses at week 12 as compared to placebo (PASI 90: 1.2\%, 1.5\%; PASI 100: 1.2\%, 0.0\%) and etanercept (PASI 90: 20.7\%; PASI 100: 4.3\%).

In the randomized, double-blind, controlled Phase III trial CLEAR, the clinical efficacy of secukinumab for psoriasis was evaluated head-to-head against ustekinumab. ${ }^{14}$ The primary endpoint for this study was the proportion of patients treated with secukinumab achieving PASI 90 at week 16 as compared to ustekinumab. This study met the primary endpoint, with secukinumab demonstrating a superior PASI 90 response at week 16 compared to ustekinumab $(79.0 \%$ vs $57.6 \%$ ). Patients' clinical responses to secukinumab at 12 weeks were notably higher than the clinical responses observed at the same time point in ERASURE and FIXTURE, with $91.0 \%$ achieving PASI 75, 72.8\% achieving PASI 90, and 38.9\% achieving PASI 100 (Table 1). The clinical response to secukinumab was sustained at week 52 , with superior efficacy as compared to ustekinumab noted in PASI 75 (92.5\% vs $79.5 \%$ ), PASI 90 (76.2\% vs $60.6 \%$ ), and PASI $100(45.9 \%$ vs $36.7 \%){ }^{15}$

Another randomized, double-blind controlled Phase III trial was conducted to assess the optimal dosing for secukinumab in plaque psoriasis. In this study, SCULPTURE, secukinumab retreatment-as-needed was compared to a fixedinterval regimen. ${ }^{16}$ Patients achieving PASI 75 response at week 12 were randomized 1:1 to fixed-interval dosing of secukinumab every 4 weeks or retreatment-as-needed every 4 weeks upon loss of PASI 75 response plus loss of more than $20 \%$ maximal PASI improvement. The primary endpoint for this study was non-inferiority of retreatment-as-needed compared to fixed-interval dosing for maintaining PASI 75, but this primary endpoint was not achieved, as significantly more patients on fixed-interval maintained PASI 75 compared to retreatment-as-needed (78.2\% vs 67.7\%). On 5-year follow-up of the SCULPTURE study, patients demonstrated sustained responses to secukinumab, with $79.2 \%$ achieving PASI 75 , $59.5 \%$ achieving PASI 90 , and $37.5 \%$ achieving PASI $100 .{ }^{17}$

The clinical efficacy of secukinumab for psoriasis was evaluated with secondary endpoints assessing the usability and tolerability of a prefilled syringe in FEATURE, a randomized, double-blind, placebo-controlled Phase III trial. ${ }^{18}$ The coprimary endpoints for this study were the proportions of patients achieving PASI 75 and IGA 0/1 at week 12 as compared to placebo. These coprimary endpoints were met, with significantly more patients treated with secukinumab achieving PASI 75 (75.9\% vs 0\%) and IGA 0/1 (69.0\% vs $0 \%$ ) response as compared to placebo. Additionally, $60.3 \%$ and $43.1 \%$ of patients treated with secukinumab achieved PASI 90 and PASI 100 at 12 weeks, respectively.

The clinical efficacy of secukinumab for psoriasis was evaluated with secondary endpoints assessing the usability and tolerability of an auto-injector pen in JUNCTURE, another randomized, double-blind, placebo-controlled Phase III trial. ${ }^{19}$ The coprimary endpoints for this study were the proportions of patients achieving PASI 75 and IGA 0/1 at week 12 as compared to placebo. These coprimary endpoints were achieved, with significantly more patients treated with secukinumab achieving PASI 75 (86.7\% vs 3.3\%) and IGA $0 / 1$ (73.3\% vs 0\%). Additionally, 55.0\% and $26.7 \%$ of patients achieved PASI 90 and PASI 100 at 12 weeks, respectively. Patients demonstrated sustained responses to secukinumab at week 52, with $81.4 \%$ achieving PASI 75 , $64.1 \%$ achieving PASI 90, and 38.8\% achieving PASI $100 .{ }^{19}$

In its Phase III trials, secukinumab has demonstrated efficacy for plaque psoriasis similar to other IL-17 inhibitors (Table 2). Notably, it has shown superiority over both etanercept and ustekinumab in head-to-head comparisons. Secukinumab offers a highly efficacious treatment option for patients with moderate-to-severe psoriasis, and may be a preferred treatment option for patients who have disease recalcitrant to treatment with TNF- $\alpha$ inhibitors or IL-12/23 inhibitors.

\section{Efficacy in difficult-to-treat areas of psoriasis}

Secukinumab has also demonstrated efficacy for psoriasis located in difficult-to-treat areas, including the scalp, palms and soles, and the nails. ${ }^{20,21}$ In a randomized, double-blind, placebo-controlled Phase III trial of patients with scalp psoriasis, treatment with $300 \mathrm{mg}$ secukinumab for 12 weeks improved scalp disease severity as compared to placebo with respect to $\geq 90 \%$ reduction in Psoriasis Scalp Severity Index ( $52.9 \%$ vs $2.0 \%)$ and scalp only IGA $0 / 1(56.9 \%$ vs $5.9 \%){ }^{22}$ In the randomized, double-blind, placebo-controlled GESTURE study of patients with non-pustular palmoplantar psoriasis, treatment with $300 \mathrm{mg}$ secukinumab for 16 weeks resulted in significant improvements in palmoplantar psoriasis disease severity, as measured by Palmoplantar Investigator's Global Assessment $0 / 1$ (33.2\% vs $1.5 \%){ }^{23}$ In the randomized, double-blind, placebo-controlled Phase III trial of patients with nail psoriasis, TRANSFIGURE, treatment with $300 \mathrm{mg}$ secukinumab for 16 weeks significantly decreased Nail Psoriasis Severity Index as compared to 
Table 2 Clinical efficacy of biologic treatments for plaque psoriasis in pivotal Phase III trials

\begin{tabular}{|c|c|c|c|c|c|c|}
\hline Drug/Trial & Dose & Frequency & Contraindications & PASI 75a & PASI 90a & PASI 100 \\
\hline \multicolumn{7}{|l|}{ IL-23 inhibitors } \\
\hline Ustekinumab & $45 \mathrm{mg}$ & 12 weeks & None & & & \\
\hline PHOENIX I & & & & $67 \%$ & $42 \%$ & $13 \%$ \\
\hline PHOENIX 2 & & & & $67 \%$ & $42 \%$ & $18 \%$ \\
\hline ACCEPT & & & & $68 \%$ & $36 \%$ & $16 \%$ \\
\hline Guselkumab & $100 \mathrm{mg}$ & 8 weeks & None & & & \\
\hline VOYAGE I & & & & $91 \%$ & $73 \%$ & $37 \%$ \\
\hline VOYAGE II & & & & $86 \%$ & $70 \%$ & $34 \%$ \\
\hline Tildrakizumab & $100 \mathrm{mg}$ & 12 weeks & None & & & \\
\hline RESURFACE I & & & & $64 \%$ & $35 \%$ & $14 \%$ \\
\hline RESURFACE 2 & & & & $61 \%$ & $39 \%$ & $12 \%$ \\
\hline Risankizumab ${ }^{\mathrm{b}}$ & $150 \mathrm{mg}$ & 12 weeks & None & & & \\
\hline ultIMMa-I & & & & - & $75 \%$ & $36 \%$ \\
\hline ultIMMa-2 & & & & - & $75 \%$ & $51 \%$ \\
\hline IMMvent & & & & - & $72 \%$ & $40 \%$ \\
\hline IMMhance & & & & $89 \%$ & $73 \%$ & $47 \%$ \\
\hline \multicolumn{7}{|l|}{ IL-I 7 inhibitors } \\
\hline Brodalumab & $210 \mathrm{mg}$ & 2 weeks & Crohn's disease & & & \\
\hline AMAGINE-I & & & & $83 \%$ & $70 \%$ & $42 \%$ \\
\hline AMAGINE-2 & & & & $86 \%$ & - & $44 \%$ \\
\hline AMAGINE-3 & & & & $85 \%$ & - & $37 \%$ \\
\hline Secukinumab & $300 \mathrm{mg}$ & 4 weeks & Hypersensitivity to & & & \\
\hline ERASURE & & & drug & $82 \%$ & $59 \%$ & $29 \%$ \\
\hline FIXTURE & & & & $77 \%$ & $54 \%$ & $24 \%$ \\
\hline Ixekizumab & $80 \mathrm{mg}$ & 4 weeks & Hypersensitivity to & & & \\
\hline UNCOVER-I & & & drug & $83 \%$ & $65 \%$ & $34 \%$ \\
\hline UNCOVER-2 & & & & $78 \%$ & $60 \%$ & $31 \%$ \\
\hline UNCOVER-3 & & & & $84 \%$ & $65 \%$ & $35 \%$ \\
\hline
\end{tabular}

Notes: Adapted from Yang et al (2018). ${ }^{46}$ aMeasured at 12 weeks, except guselkumab and risankizumab which were measured at 16 weeks. ${ }^{\text {DNot }}$ currently approved for the treatment of plaque psoriasis. PASI 100, $\geq 100 \%$ improvement in PASI from baseline; PASI $75, \geq 75 \%$ improvement in PASI from baseline; PASI $90, \geq 90 \%$ improvement in PASI from baseline.

Abbreviation: PASI, Psoriasis Area and Severity Index.

placebo (-45.4\% vs $-11.2 \%) .{ }^{24}$ Additionally, in a singlearm, open-label Phase III trial of patients with generalized pustular psoriasis, treatment with $150 \mathrm{mg}$ secukinumab with up-titration to $300 \mathrm{mg}$ as needed, resulted in treatment success in $83.3 \%$ of patients as measured by Clinical Global Impression. ${ }^{25}$ Secukinumab may benefit patients with isolated scalp, palmoplantar, or nail psoriasis.

\section{Efficacy in psoriatic arthritis}

Two pivotal randomized, double-blind, placebo-controlled Phase III trials evaluated the efficacy of $150 \mathrm{mg}$ secukinumab in patients with active psoriatic arthritis, FUTURE-1 and FUTURE-2. ${ }^{26,27}$ The primary endpoint for both studies was the proportion of patients achieving $\geq 20 \%$ improvement in American College of Rheumatology score 20 (ACR20) at week 24 as compared to placebo. Both trials achieved this primary endpoint, with a significantly greater proportion of patients at week 24 achieving ACR20 compared to placebo (FUTURE-1: $50.0 \%$ vs 17.3\%, FUTURE-2: 51.0\% vs $15.3 \%$ ) (Table 3). Patients also achieved better ACR50 response (FUTURE-1: $34.7 \%$ vs $7.4 \%$, FUTURE-2: $35.0 \%$ vs $18.2 \%$ ) and slight reductions in joint structural damage as measured by Sharp score, as compared to placebo. These improvements were sustained through 52 weeks, with 59.9\% of patients treated with secukinumab reporting ACR20 response. ${ }^{28}$ In the FUTURE-1 cohort, $84.3 \%$ of patients demonstrated no radiographic progression of joint damage at 2 years. ${ }^{29}$

The clinical efficacy of secukinumab for psoriatic arthritis was evaluated with secondary endpoints assessing the usability and tolerability of an auto-injector pen in FUTURE-3, a randomized, double-blind, placebo-controlled Phase III trial. ${ }^{30}$ The primary endpoint for this study was the proportion of patients achieving ACR20 at week 24 as compared to placebo. This primary endpoint was achieved, with significantly more patients treated with $150 \mathrm{mg}$ secukinumab achieving ACR 20 (42.0\% vs $16.1 \%$ ). Additionally, $18.8 \%$ of patients achieved ACR50 at 24 weeks. 
Table 3 Summary of key Phase III clinical trial results of secukinumab for the treatment of psoriatic arthritis

\begin{tabular}{|c|c|c|c|c|c|c|c|c|}
\hline Trial & Year & $\mathbf{n}$ & Treatment $(n)$ & ACR20 & ACR50 & $\begin{array}{l}\text { Change in } \\
\text { HAQ-DI }\end{array}$ & $\begin{array}{l}\text { Change in } \\
\text { DAS-CRP }\end{array}$ & $\begin{array}{l}\text { Change in } \\
\text { SF-36 PCS }\end{array}$ \\
\hline FUTURE-I ${ }^{26}$ & 2015 & 606 & $\begin{array}{l}\text { Secukinumab, I50 mg (202) } \\
\text { Secukinumab, } 75 \text { mg (202 } \\
\text { Placebo (202) }\end{array}$ & $\begin{array}{l}50.0 \% \\
50.5 \% \\
17.3 \%\end{array}$ & $\begin{array}{l}34.7 \% \\
30.7 \% \\
7.4 \%\end{array}$ & $\begin{array}{l}-0.40 \\
-0.41 \\
-0.17\end{array}$ & $\begin{array}{l}-1.62 \\
-1.67 \\
-0.77\end{array}$ & $\begin{array}{l}5.91 \\
5.41 \\
1.82\end{array}$ \\
\hline FUTURE-2 ${ }^{27}$ & 2015 & 397 & $\begin{array}{l}\text { Secukinumab, } 300 \text { mg (100) } \\
\text { Secukinumab, } 150 \mathrm{mg}(100) \\
\text { Secukinumab, } 75 \mathrm{mg}(99) \\
\text { Placebo (98) }\end{array}$ & $\begin{array}{l}54.0 \% \\
51.0 \% \\
29.3 \% \\
15.3 \%\end{array}$ & $\begin{array}{l}35.0 \% \\
35.0 \% \\
18.2 \% \\
7.1 \%\end{array}$ & $\begin{array}{l}-0.56 \\
-0.48 \\
-0.32 \\
-0.31\end{array}$ & $\begin{array}{l}-1.61 \\
-1.58 \\
-1.12 \\
-0.96\end{array}$ & $\begin{array}{l}7.25 \\
6.39 \\
4.38 \\
1.95\end{array}$ \\
\hline FUTURE-3 ${ }^{30}$ & 2018 & 416 & $\begin{array}{l}\text { Secukinumab, } 300 \text { mg (I39) } \\
\text { Secukinumab, I50 mg (I38) } \\
\text { Placebo (I37) }\end{array}$ & $\begin{array}{l}48.2 \% \\
42.0 \% \\
16.1 \%\end{array}$ & $\begin{array}{l}34.5 \% \\
18.8 \% \\
8.8 \%\end{array}$ & $\begin{array}{l}-0.38 \\
-0.27 \\
-0.17\end{array}$ & $\begin{array}{l}-1.56 \\
-1.24 \\
-0.64\end{array}$ & $\begin{array}{l}6.46 \\
3.42 \\
2.94\end{array}$ \\
\hline FUTURE-5' & 2018 & 996 & $\begin{array}{l}\text { Secukinumab, } 300 \mathrm{mg} \text { (222) } \\
\text { Secukinumab, } 150 \mathrm{mg} \text { with } \\
\text { loading dose ( } 220) \\
\text { Secukinumab } 150 \mathrm{mg} \text { without } \\
\text { loading dose (222) } \\
\text { Placebo (332) }\end{array}$ & $\begin{array}{l}62.6 \% \\
55.5 \% \\
59.5 \% \\
27.4 \%\end{array}$ & $\begin{array}{l}39.6 \% \\
35.9 \% \\
32.0 \% \\
8.1 \%\end{array}$ & $\begin{array}{l}-0.55 \\
-0.44 \\
-0.45 \\
-0.21\end{array}$ & $\begin{array}{l}-1.49 \\
-1.29 \\
-1.29 \\
-0.63\end{array}$ & $\begin{array}{l}- \\
- \\
- \\
-\end{array}$ \\
\hline
\end{tabular}

Notes: Endpoints for all trials were measured at week 24, except for FUTURE-5 which were measured at week 16 . ACR20, $\geq 20 \%$ improvement in ACR from baseline; ACR50, $\geq 50 \%$ improvement in ACR from baseline.

Abbreviations: ACR, American College of Rheumatology score; DAS-CRP, 28-joint Disease Activity Score on the basis of levels of C-reactive protein; HAQ-DI, Health Assessment Questionnaire-Disability Index; SF-36 PCS, Short Form 36-Item Physical Component Summary Score of the Medical Outcomes Survey.

The efficacy of secukinumab for treating the clinical signs and symptoms of psoriatic arthritis, as well as radiographic progression, was evaluated in the randomized, double-blind, placebo-controlled Phase III trial FUTURE- $5 .{ }^{31}$ The primary endpoint for this study was the proportion of patients achieving ACR20 response at week 16 as compared to placebo, with secondary endpoints assessing changes in the radiographic progression of the disease. This primary endpoint was achieved, with significantly more patients treated with $150 \mathrm{mg}$ secukinumab achieving ACR20 (57.5\% vs 27.4\%). Additionally, $33.9 \%$ and $16.5 \%$ of patients on $150 \mathrm{mg}$ secukinumab achieved ACR50 and ACR70, respectively. In this study, radiographic progression was significantly inhibited at week 24 as compared to placebo.

\section{Safety}

In pooled analyses of Phase II and III trials, secukinumab was found to be well-tolerated. ${ }^{32,33}$ Currently published clinical trials have demonstrated a favorable safety profile for secukinumab for up to 5 years of treatment. ${ }^{17,32}$ No cases of reactivation of latent tuberculosis have been reported with secukinumab treatment in its clinical trials. ${ }^{33}$ Secukinumab treatment has not been associated with any increased risk of anxiety or depression. Neutropenia was observed rarely during clinical trials of secukinumab, but most cases were transient and reversible, without association with serious infection. ${ }^{12,33}$
Common adverse effects of secukinumab treatment include headache and nasopharyngitis. Patients treated with secukinumab have been shown, in Phase II and III trials, to have an increased risk of mucocutaneous candidiasis, which can be successfully treated with oral or topical therapies and typically does not require discontinuation of secukinumab therapy. ${ }^{32,33}$ Although secukinumab has not been shown to increase the risk of IBD flares, secukinumab should be avoided in patients with IBD. ${ }^{12}$

The safety profile of secukinumab is comparable to that of other IL-17 inhibitors, and continues to be well-tolerated for up to 5 years of treatment. In patients for whom the drug is not contraindicated, secukinumab is only associated with mild side effects that rarely lead to cessation of therapy. However, TNF- $\alpha$ inhibitors and ustekinumab have more safety data spanning far longer treatment durations, and may thus be a more optimal treatment option for patients concerned about the long-term safety of biologic therapies or medically-complex patients.

\section{Discussion Onset of action}

Many biologics are available for the treatment of plaque psoriasis, but these therapies have varying efficacy and safety profiles (Table 1). In general, IL-17 and IL-23 inhibitors demonstrate higher efficacy than older TNF- $\alpha$ inhibitors, while sub-analyses of the onset of action of biologic therapies 
demonstrated that IL-17 inhibitors act more quickly than ustekinumab and TNF- $\alpha$ inhibitors. ${ }^{34}$ Of note, secukinumab resulted in PASI 75 response in $25 \%$ of patients in 3.0 weeks, and achieved an average of $50 \%$ reduction in PASI score in 3.0 weeks. Brodalumab (Siliq, Valeant Pharmaceuticals, Bridgewater, NJ, USA) had the most rapid onset of action among any biologic therapy in this analysis, with $25 \%$ of patients achieving PASI 75 at 2.1 weeks, and achieving an average of $50 \%$ reduction in PASI score at 1.8 weeks.

These data demonstrate that IL-17 inhibitors are ideal for psoriasis patients who require rapid clearance of their skin. Although a chronic disease, certain patients may benefit from more rapid response than others, such as patients with significantly impaired quality of life. Discouraged patients with recalcitrant disease may lose confidence about treatment if they do not observe efficient improvement of their skin symptoms, which can lead to poor medication adherence. ${ }^{35}$ Thus, it is important to treat these patients early with rapid-acting biologic therapies, a niche that IL-17 inhibitors fill well.

Currently-approved IL-17 inhibitors - secukinumab, brodalumab, and ixekizumab - all achieve an average of $50 \%$ reduction in PASI within 2 weeks. ${ }^{34}$ However, the most rapidly-acting IL-17 inhibitor, brodalumab, has a black box warning for depression. Although the actual risk for suicidality and depression with brodalumab is uncertain, ${ }^{36}$ this possible risk must be discussed with patients prior to prescribing brodalumab. Secukinumab has no black box warnings that need to be discussed prior to initiating treatment, and no increased risk of depression or suicidality, as observed in its Phase III clinical trials. Thus, patients concerned about the side effect profiles of biologics are sometimes more amenable to starting on secukinumab, rather than brodalumab or TNF- $\alpha$ inhibitors, which have multiple black box warnings.

\section{Convenience}

Patient convenience should also be considered when selecting a biologic medication for psoriasis patients. IL-23 and IL-12/23 inhibitors are dosed more infrequently than IL-17 inhibitors (Table 2), and may be preferable for patients who require supervision for medication administration by a health care professional or who have issues with medication compliance. However, secukinumab is still dosed more infrequently than some TNF- $\alpha$ inhibitors that are dosed every 1-2 weeks.

The JUNCTURE and FEATURE Phase III trials demonstrated that secukinumab administered by autoinjector pen or prefilled syringe continues to be well-tolerated at 1 year under the currently-approved dosing regimen. ${ }^{19,37}$ No increased risk of injection-site reactions has been reported with secukinumab treatment with either method of administration. Patients who are able to comply with a regular monthly dosing regimen may benefit from secukinumab treatment due to its convenience over older biologic therapies, as well as for other reasons outlined in this manuscript.

\section{Treatment of comorbid disease}

Up to $40 \%$ of psoriasis patients have or will develop psoriatic arthritis during their lifetimes, so treatment of joint symptoms in addition to skin symptoms is critical to prevent irreversible joint damage. Secukinumab is one of six biologics currently approved for the treatment of both psoriatic arthritis and psoriasis vulgaris, a group that also includes etanercept, adalimumab, infliximab, ustekinumab, and ixekizumab. Secukinumab results in excellent ACR response after 24 weeks of treatment, but this biologic also inhibits radiographic joint damage in psoriatic arthritis patients for up to 2 years. ${ }^{29}$ Thus, secukinumab offers a long-term treatment option for psoriatic arthritis patients that does not just slow joint damage, but prevents further damage from occurring.

Almost half of psoriasis patients without psoriatic arthritis harbor subclinical joint inflammation, thought to be an antecedent to inflammatory arthritis. ${ }^{38}$ Of these psoriasis patients with subclinical synovitis and arthralgia symptoms at baseline, 55\% developed psoriatic arthritis according to Classification of Psoriatic Arthritis criteria within 1 year. Early intervention is of paramount importance for arthritis patients, as joint damage is permanent. ${ }^{39}$ Thus, secukinumab treatment in patients with nonspecific joint pain may be of benefit, due to the high risk of progression to joint involvement.

\section{Cost-effectiveness}

Biologics' cost is a primary concern for dermatologists when selecting treatment for moderate-to-severe psoriasis patients. ${ }^{40}$ Current estimates of the annual cost of achieving PASI 75 response with secukinumab range from $\$ 75,671$ to $\$ 105,131$ (US\$). ${ }^{41,42}$ Previous analyses from Europe have shown secukinumab to be more cost-effective than TNF- $\alpha$ inhibitors as a first-line agent due to its superior clinical efficacy, ultimately resulting in cost savings. ${ }^{43}$ However, cost estimates for all biologics vary widely in the literature, and are accompanied by high levels of uncertainty. ${ }^{44,45}$ Further research is needed to evaluate the cost-effectiveness of all biologics for psoriasis.

\section{Conclusion}

Dermatologists have a plethora of options available for the treatment of patients with moderate-to-severe psoriasis, but the decision of which medication to choose is often difficult. 
Secukinumab is a highly-efficacious, fast-acting biologic therapy with a relatively favorable safety profile that can be considered in patients requiring rapid clearance of their psoriasis and patients with psoriasis in difficult-to-treat areas, such as the scalp, palms and soles, or nails. Additionally, secukinumab is a preferred treatment for patients with comorbid psoriatic arthritis or arthralgia symptoms, due to its ability to inhibit progression of arthritic disease. Careful consideration of clinical efficacy, safety, cost, convenience, onset of action, and management of comorbid disease is necessary when selecting treatment for individual patients.

\section{Disclosure}

WL has received research grant funding from Abbvie, Janssen, Novartis, and Pfizer. WL is funded in part by grants from the National Institutes of Health (R01AR065174, U01AI1 19125). The authors report no other conflicts of interest in this work.

\section{References}

1. Gupta MA, Schork NJ, Gupta AK, Kirkby S, Ellis CN. Suicidal ideation in psoriasis. Int J Dermatol. 1993;32(3):188-190.

2. Kurd SK, Troxel AB, Crits-Christoph P, Gelfand JM. The risk of depression, anxiety, and suicidality in patients with psoriasis: a populationbased cohort study. Arch Dermatol. 2010;146(8):891-895.

3. Dowlatshahi EA, Wakkee M, Arends LR, Nijsten T. The prevalence and odds of depressive symptoms and clinical depression in psoriasis patients: a systematic review and meta-analysis. J Invest Dermatol. 2014;134(6):1542-1551.

4. Mehta NN, Azfar RS, Shin DB, Neimann AL, Troxel AB, Gelfand JM. Patients with severe psoriasis are at increased risk of cardiovascular mortality: cohort study using the General Practice Research Database. Eur Heart J. 2010;31(8):1000-1006.

5. Gelfand JM, Neimann AL, Shin DB, Wang X, Margolis DJ, Troxel AB. Risk of myocardial infarction in patients with psoriasis. JAMA. 2006;296(14):1735-1741.

6. Rapp SR, Feldman SR, Exum ML, Fleischer AB, Reboussin DM. Psoriasis causes as much disability as other major medical diseases. $\mathrm{J} \mathrm{Am}$ Acad Dermatol. 1999;41(3 Pt 1):401-407.

7. Gelfand JM, Troxel AB, Lewis JD, et al. The risk of mortality in patients with psoriasis: results from a population-based study. Arch Dermatol. 2007;143(12):1493-1499.

8. Villani AP, Rouzaud M, Sevrain M, et al. Prevalence of undiagnosed psoriatic arthritis among psoriasis patients: Systematic review and meta-analysis. J Am Acad Dermatol. 2015;73(2):242-248.

9. Bhutani T, Patel T, Koo B, Nguyen T, Hong J, Koo J. A prospective, interventional assessment of psoriasis quality of life using a nonskinspecific validated instrument that allows comparison with other major medical conditions. J Am Acad Dermatol. 2013;69(2):e79-e88.

10. Gelfand JM. Commentary: Does biologic treatment of psoriasis lower the risk of cardiovascular events and mortality?: A critical question that we are only just beginning to answer. $\mathrm{J}$ Am Acad Dermatol. 2018;79(1):69-70.

11. Wu JJ, Sundaram M, Cloutier M, et al. The risk of cardiovascular events in psoriasis patients treated with tumor necrosis factor- $\alpha$ inhibitors versus phototherapy: An observational cohort study. J Am Acad Dermatol. 2018;79(1):60-68.

12. COSENTYX (secukinumab) [package insert]. In. East Hanover, NJ: Novartis Pharmaceuticals Corporation. 2016.
13. Langley RG, Elewski BE, Lebwohl M, et al. Secukinumab in plaque psoriasis--results of two phase 3 trials. $N$ Engl J Med. 2014;371(4): 326-338.

14. Thaçi D, Blauvelt A, Reich K, et al. Secukinumab is superior to ustekinumab in clearing skin of subjects with moderate to severe plaque psoriasis: CLEAR, a randomized controlled trial. J Am Acad Dermatol. 2015;73(3):400-409.

15. Blauvelt A, Reich K, Tsai TF, et al. Secukinumab is superior to ustekinumab in clearing skin of subjects with moderate-to-severe plaque psoriasis up to 1 year: Results from the CLEAR study. J Am Acad Dermatol. 2017;76(1):60-69.

16. Mrowietz U, Leonardi CL, Girolomoni G, et al. Secukinumab retreatment-as-needed versus fixed-interval maintenance regimen for moderate to severe plaque psoriasis: A randomized, double-blind, noninferiority trial (SCULPTURE). J Am Acad Dermatol. 2015;73(1):27-36.

17. Bissonnette R, Luger T, Thaci D. Secukinumab demonstrates high sustained efficacy and a favourable safety profile in patients with moderate-to-severe psoriasis through 5 years of treatment (SCULPTURE Extension Study). J Eur Acad Dermatol Venereol. 2018;32(9):1507-1514.

18. Blauvelt A, Prinz JC, Gottlieb AB, et al. Secukinumab administration by pre-filled syringe: efficacy, safety and usability results from a randomized controlled trial in psoriasis (FEATURE). Br J Dermatol. 2015;172(2):484-493.

19. Lacour JP, Paul C, Jazayeri S, et al. Secukinumab administration by autoinjector maintains reduction of plaque psoriasis severity over 52 weeks: results of the randomized controlled JUNCTURE trial. J Eur Acad Dermatol Venereol. 2017;31(5):847-856.

20. Armstrong AW, Vender R, Kircik L. Secukinumab in the Treatment of Palmoplantar, Nail, Scalp, and Pustular Psoriasis. J Clin Aesthet Dermatol. 2016;9(6 Suppl 1):S12-s16.

21. Sanchez IM, Sorenson E, Levin E, Liao W. The Efficacy of Biologic Therapy for the Management of Palmoplantar Psoriasis and Palmoplantar Pustulosis: A Systematic Review. Dermatol Ther. 2017;7(4):425-446.

22. Bagel J, Duffin KC, Moore A, et al. The effect of secukinumab on moderate-to-severe scalp psoriasis: Results of a 24-week, randomized, double-blind, placebo-controlled phase $3 \mathrm{~b}$ study. J Am Acad Dermatol. 2017;77(4):667-674.

23. Gottlieb A, Sullivan J, van Doorn M, et al. Secukinumab shows significant efficacy in palmoplantar psoriasis: Results from GESTURE, a randomized controlled trial. J Am Acad Dermatol. 2017;76(1):70-80.

24. Reich K, Sullivan J, Arenberger P. Secukinumab is effective in subjects with moderate to severe plaque psoriasis with significant nail involvement: 16 week results from the TRANSFIGURE study. 23rd World Congress of Dermatology; Vancouver, Canada; June 8-15, 2015.

25. Imafuku S, Honma M, Okubo Y, et al. Efficacy and safety of secukinumab in patients with generalized pustular psoriasis: A 52-week analysis from phase III open-label multicenter Japanese study. $J$ Dermatol. 2016;43(9):1011-1017.

26. Mease PJ, Mcinnes IB, Kirkham B, et al. Secukinumab Inhibition of Interleukin-17A in Patients with Psoriatic Arthritis. $N$ Engl J Med. 2015;373(14):1329-1339.

27. McInnes IB, Mease PJ, Kirkham B, et al. Secukinumab, a human antiinterleukin-17A monoclonal antibody, in patients with psoriatic arthritis (FUTURE 2): a randomised, double-blind, placebo-controlled, phase 3 trial. Lancet. 2015;386(9999):1137-1146.

28. McInnes IB, Mease PJ, Ritchlin CT, et al. Secukinumab sustains improvement in signs and symptoms of psoriatic arthritis: 2 year results from the phase 3 FUTURE 2 study. Rheumatology. 2017;56(11): 1993-2003.

29. Kavanaugh A, Mease PJ, Reimold AM, et al. Secukinumab for LongTerm Treatment of Psoriatic Arthritis: A Two-Year Followup From a Phase III, Randomized, Double-Blind Placebo-Controlled Study. Arthritis Care Res. 2017;69(3):347-355. 
30. Nash P, Mease PJ, Mcinnes IB, et al. Efficacy and safety of secukinumab administration by autoinjector in patients with psoriatic arthritis: results from a randomized, placebo-controlled trial (FUTURE 3). Arthritis Res Ther. 2018;20(1):47.

31. Mease P, van der Heijde D, Landewé R, et al. Secukinumab improves active psoriatic arthritis symptoms and inhibits radiographic progression: primary results from the randomised, double-blind, phase III FUTURE 5 study. Ann Rheum Dis. 2018;77(6):890-897.

32. Blauvelt A. Safety of secukinumab in the treatment of psoriasis. Expert Opin Drug Saf. 2016;15(10):1413-1420.

33. van de Kerkhof PC, Griffiths CE, Reich K, et al. Secukinumab longterm safety experience: A pooled analysis of 10 phase II and III clinical studies in patients with moderate to severe plaque psoriasis. $\mathrm{J} \mathrm{Am} \mathrm{Acad}$ Dermatol. 2016;75(1):83-98.

34. Papp KA, Lebwohl MG. Onset of Action of Biologics in Patients With Moderate-to-Severe Psoriasis. J Drugs Dermatol. 2017;17(3):247-250.

35. Zschocke I, Ortland C, Reich K. Evaluation of adherence predictors for the treatment of moderate to severe psoriasis with biologics: the importance of physician-patient interaction and communication. $J$ Eur Acad Dermatol Venereol. 2017;31(6):1014-1020.

36. Lebwohl MG, Papp KA, Marangell LB, et al. Psychiatric adverse events during treatment with brodalumab: Analysis of psoriasis clinical trials. J Am Acad Dermatol. 2018;78(1):81-89.

37. Gottlieb AB, Blauvelt A, Prinz JC, et al. Secukinumab Self-Administration by Prefilled Syringe Maintains Reduction of Plaque Psoriasis Severity Over 52 Weeks: Results of the FEATURE Trial. J Drugs Dermatol. 2016;15(10):1226-1234.

38. Faustini F, Simon D, Oliveira I, et al. Subclinical joint inflammation in patients with psoriasis without concomitant psoriatic arthritis: a cross-sectional and longitudinal analysis. Ann Rheum Dis. 2016;75(12):2068-2074.
39. Boyd T, Kavanaugh A. Novel Treatment Concepts in Psoriatic Arthritis. Rheum Dis Clin North Am. 2015;41(4):739-754.

40. van de Kerkhof PC, Reich K, Kavanaugh A, et al. Physician perspectives in the management of psoriasis and psoriatic arthritis: results from the population-based Multinational Assessment of Psoriasis and Psoriatic Arthritis survey. J Eur Acad Dermatol Venereol. 2015;29(10):2002-2010.

41. Wu JJ, Feldman SR, Rastogi S, Menges B, Lingohr-Smith M, Lin J. Comparison of the cost-effectiveness of biologic drugs used for moderate-to-severe psoriasis treatment in the United States. $J$ Dermatolog Treat. 2018:1-6.

42. Armstrong AW, Betts KA, Signorovitch JE, et al. Number needed to treat and costs per responder among biologic treatments for moderateto-severe psoriasis: a network meta-analysis. Curr Med Res Opin. 2018;34(7):1-9.

43. Augustin M, Mcbride D, Gilloteau I, O'Neill C, Neidhardt K, Graham $\mathrm{CN}$. Cost-effectiveness of secukinumab as first biologic treatment, compared with other biologics, for moderate to severe psoriasis in Germany. J Eur Acad Dermatol Venereol. 2018. [Epub ahead of print].

44. Kromer C, Celis D, Sonntag D, Peitsch WK. Biologicals and small molecules in psoriasis: A systematic review of economic evaluations. PLoS One. 2018;13(1):e0189765.

45. Hamilton MP, Ntais D, Griffiths CE, Davies LM, Identification and Management of Psoriasis-Associated ComorbidiTy (IMPACT) Team. Psoriasis treatment and management - a systematic review of full economic evaluations. Br J Dermatol. 2015;172(3):574-583.

46. Yang EJ, Sanchez IM, Beck K, Sekhon S, Wu JJ, Bhutani T. Guselkumab for the treatment of moderate-to-severe plaque psoriasis. Expert Rev Clin Pharmacol. 2018;11(4):333-344.
Psoriasis: Targets and Therapy

\section{Publish your work in this journal}

Psoriasis: Targets and Therapy is international, peer-reviewed, open access journal focusing on psoriasis, nail psoriasis, psoriatic arthritis and related conditions, identification of therapeutic targets and the optimal use of integrated treatment interventions to achieve improved outcomes

\section{Dovepress}

and quality of life. Visit http://www.dovepress.com/testimonials.php to read real quotes from published authors. 